\title{
Prokaryotic Expression and Monoclonal Antibody Preparation of Rabies Virus Phosphoprotein
}

\author{
Juan Hu, ${ }^{1}$ Xueshan Xia, ${ }^{1}$ Ming Yang, ${ }^{1}$ Yuzhu Song, ${ }^{1}$ Qinqin Han, ${ }^{1}$ Qiang Chen, ${ }^{1}$ Jie Zan, ${ }^{2}$ and Jinyang \\ Zhang, ${ }^{1, *}$ \\ ${ }^{1}$ Research Center of Molecular Medicine of Yunnan Province, Faculty of Life Science and Technology, Kunming University of Science and Technology, Kunming 650500, PR \\ China \\ ${ }^{2}$ Biomedical Research Institute, Guangdong University of Technology, Guangzhou 510090, PR China \\ "Corresponding author: Jinyang Zhang, Faculty of Life Science and Technology, Kunming University of Science and Technology, 727 Jingming South Road, Kunming 650500, P. \\ R. China. Tel: +86-8716593-9528, Fax: +86-87165939528, E-mail: jyzhang@kmust.edu.cn
}

Received 2016 December 12; Revised 2017 May 11; Accepted 2017 June 24.

\begin{abstract}
Background: Rabies is a zoonotic infectious disease that infects the human and animal central nervous system. Worldwide, especially in low-income countries, this disease is still a burden for public health. Among the rabies virus proteins, phosphoprotein plays a very important role in viral infection, and this research found that immunization of rabies virus vaccines could widely induce antibody responses against phosphoprotein, therefore rabies virus phosphoprotein may be a useful target for development of rapid and low cost serological diagnosis test, and therapeutic drugs.

Objectives: The aim of this study was to prepare anti-rabies virus phosphoprotein monoclonal antibody, which is used for rapid detection and diagnosis of rabies virus infection.

Methods: The phosphoprotein gene was amplified by the polymerase chain reaction (PCR), and sub-cloned in a his-tagged prokaryotic expression vector to generate a recombinant plasmid named pET-32a-RABV-P. Recombinant RABV-P was induced by isopropyl- $\beta$ D-Thiogalactopyranoside (IPTG), and then purified by the Ni-NTA purification system. Immunization of BALB/c mice with the recombinant protein was performed, and the spleen cells of the immunized mice and SP2/0 myeloma cells were fused together to obtain the monoclonal cell strains, and then identification of the characteristics of the antibody by the enzyme linked immunosorbent assay (ELISA), western blotting, and indirect immunofluorescence assay was done.

Results: The prokaryotic expression vector of pET-32a-RABV-P was successfully constructed. The fusion protein was expressed in Escherichia coli Rosetta and purified. After cell fusion, a hybridoma cell line 1A4 was successfully obtained. The antibody titer of the anti-RABV-P ascites reached 256,000. The results of western blotting and indirect immunofluorescence assay indicated that $1 \mathrm{~A} 4$ hybridoma cell line was able to produce specific antibodies against rabies virus phosphoprotein.

Conclusions: Recombinant rabies virus phosphoprotein could be successfully expressed in E. coli. A specific monoclonal antibody against rabies virus phosphoprotein has been successfully prepared.
\end{abstract}

Keywords: Rabies Virus, Phosphoprotein, Recombinant Protein, Monoclonal Antibody

\section{Background}

Rabies is a highly lethal disease and is still a serious threat for public health all over the world $(1,2)$. Although effective rabies vaccines have been developed for decades, effective treatment for rabies disease is still unavailable (36). The detection technique of Rabies is necessary to monitor the natural infection and evaluate the immune effect of the vaccine. Rabies virus (RABV), belonging to Lyssavirus in the family Rhabdoviridae, is composed of 11928 or 11932 nucleotides and encodes five structural proteins: nucleoprotein $(\mathrm{N})$, phosphoprotein $(\mathrm{P})$, matrix protein $(\mathrm{M})$, glycoprotein $(\mathrm{G})$, and RNA-dependent RNA polymerase $(\mathrm{L})(2,6-8)$.

The length of the phosphoprotein is $894 \mathrm{bp}$, which is located on nucleotides 1514 to 2407 of the whole genome.
Phosphoprotein is a highly hydrophilic protein and accounted for about $6 \%$ of the total protein content of the virus (9-11). Phosphoprotein is a viral RNA polymerase cofactor, and it complexes with large proteins and nucleoproteins encased in viral genomic RNA. Phosphoprotein is a multifunctional protein, and plays an important role in immune response. Through interaction with STAT1 and inhibition of interferon signal transduction pathway, phosphoprotein prevents the cell's anti-viral response after infection. Therefore, it is an important regulator of immune response $(4,12-14)$. The expression of rabies virus phosphoprotein in infected cells is second only to nucleoprotein, and it is relatively stable in structure and plays an important role in virus assembly and immune mechanism (15-17).

The pervious study performed by the authors found 
that antibody responses against phosphoprotein were strongly induced by immunization of rabies virus. Therefore, rabies virus phosphoprotein maybe a useful antigen for clinical diagnosis and treatment of rabies virus.

\section{Objectives}

This study aimed at screening anti-RABV mAbs, which is useful for rapid detection of rabies virus infection and new anti-viral drugs.

\section{Methods}

\subsection{Cell-Line and Virus}

Mouse myeloma cell-line SP2/0 was cultured at $37^{\circ} \mathrm{C}$ in RPMI-1640 (Gibco, USA), supplemented with $10 \%$ fetal bovine serum (FBS) (Transgen, China) in a $5 \%$ a $\mathrm{CO}_{2}$ humidified incubator $(18,19)$. The ethics committee of the Kunming University of Science and Technology approved the animal experiment of this study. Rabies virus HEP-Flury strain was amplified in N2a cells, and was stored at $-80^{\circ} \mathrm{C}$.

\subsection{Plasmid Construction}

$\begin{array}{ccccc}\text { The } & \text { RABV-P gene was amplified } \\ \text { by PCR } & \text { with } & \text { specific primers F (5'- }\end{array}$ CGCGAATTCATGAGCAAGATCTTTGTTAATCCGAG -3') and R (5'-GTCGACGCCGCTTAGCATGATGTGTAGCGATCCAAGT -3') (the enzyme sites EcoR I and Sal I are underlined). The amplified PCR products were double digested with EcoR I and Sal I, gel-purified, and ligated in the pET-32a (+) expression vector, doubly digested with the same restriction enzymes. The connected product was transformed to Escherichia coli Rosetta. The positive clone was confirmed by DNA sequencing. Theoretically, the resulting recombinant plasmid defined as pET-32a-RABV-P, could express a fusion protein corresponding to RABV-P.

\subsection{Expression and Purification of the Recombinant Protein}

The bacterial expression plasmid pET-32a-RABV-P was transformed to E. coli Rosetta (DE3) cells, and protein expression was induced with $1.0 \mathrm{mM}$ isopropyl- $\beta$-Dthiogalactopyranoside (IPTG) at $37^{\circ} \mathrm{C}$ for 4 to 5 hours. The cells were collected and resuspended in Phosphate Buffered Saline (PBS), and were then lysed by ultrasonication on ice. After centrifugation at $10,000 \times \mathrm{g}$ for 20 minutes at $4^{\circ} \mathrm{C}$, the precipitates were washed 3 times with washing buffer (50 mM Tris- $\mathrm{HCl}, 100 \mathrm{mmol} / \mathrm{L} \mathrm{NaCl}, \mathrm{pH}$ 7.9). Next, it was clarified by centrifugation at $10,000 \times$ $\mathrm{g}$ for 20 minutes at $4^{\circ} \mathrm{C}$; the precipitates were denatured in $8 \mathrm{M}$ urea (50 mM Tris- $\mathrm{HCl}, 100 \mathrm{mmol} / \mathrm{L} \mathrm{NaCl}, \mathrm{pH} 7.9$ ), at room temperature for 3 hours, and the lysates were centrifuged at $10,000 \times \mathrm{g}$ for 30 minutes at $4^{\circ} \mathrm{C}$, and proteins in the supernatant were purified with a column of nickelnitrilotriacetic acid (Ni2+-NTA) agarose resin. Next, denatured proteins were refolded in refolding buffer at $4^{\circ} \mathrm{C}$ overnight. Finally, the proteins were identified by SDSPAGE assays (20). The concentrationof the recombinant fusion proteins RABV-P was determined by the Bradford assay with bovine serum albumin (BSA, Amresco, USA) as a standard, and stored at $-80^{\circ} \mathrm{C}$.

\subsection{Preparation of Polyclonal Antibody Against RABV-P}

The purified recombinant RABV-P was used for antibody production in Balb/c mice. Prior to immunization, blood samples were obtained from each mouse. Blood was placed for 1 hour at $37^{\circ} \mathrm{C}$ and was then centrifuged at 5,000 rpm for 20 minutes at $4^{\circ} \mathrm{C}$. The serum was gathered as a negative control. Mice were first immunized by back multipoint subcutaneous injection using a mixture of $20 \mu \mathrm{g}$ of purified recombinant RABV-P with an equal volume of Freund's complete adjuvant (Sigma, USA). After 2-week intervals, the injections were given with a mixture of $20 \mu \mathrm{g}$ of purified recombinant RABV-P, each in incomplete Freund's adjuvant. Subsequently, the blood was obtained 1 week after the last injection. The serum was gathered according to the above method and then equal volume of glycerol was added, and the solution was stored at $-20^{\circ} \mathrm{C}$ for further use.

\subsection{Screening and Characterization of Monoclonal Antibodies}

\subsubsection{Indirect Enzyme-Linked Immunosorbent Assay (iELISA)}

Indirect Enzyme-Linked Immunosorbent Assay (iELISA) was used to determine the titer of ascites. The purified recombinant RABV-P diluted to $3 \mu \mathrm{g} / \mathrm{mL}$ in $50 \mathrm{mM}$ phosphate buffer ( $\mathrm{pH}$ 9.6) was coated on a microtiter plate at $100 \mu \mathrm{L}$ and incubated for 3 hours at $37^{\circ} \mathrm{C}$. The coated wells were washed 3 times with Phosphate-Buffered Saline (PBS) with 0.1\% Tween 20 (PBST) and then blocked with $100 \mu \mathrm{L}$ of blocking buffer (5\% skimmed milk in PBST) for 2 hours at $37^{\circ} \mathrm{C}$. After washing 3 times with PBST buffer, the coated wells were incubated with $100 \mu \mathrm{L}$ of ascites against RABV-P with different consecutive dilutions (from $1: 2000$ to $1: 256,000)$ at $37^{\circ} \mathrm{C}$ for 2 hours. After incubation, the coated cells were washed 3 times with PBST buffer followed by goat anti-mouse IgG $(\mathrm{H}+\mathrm{L})$ HRP (Southern Biotech, USA), as a secondary antibody. The optical density of each well was then measured at $450 \mathrm{~nm}$, using a microplate reader (Thermo Fisher Scientific, Finland).

\subsubsection{Western Blot Analysis}

Rabies virus infected and mock-infected N2a cells were lysed by RIPA buffer, and the protein in lysates $(20 \mu \mathrm{g})$ were separated by $12 \%$ SDS-PAGE; the gel was immersed 
in the transfer buffer. The proteins were transferred to a Nitrocellulose (NC) membrane equilibrated in transfer buffer at $100 \mathrm{~V} 160 \mathrm{~mA}$ for 60 minutes. The membrane was incubated in a blocking buffer ( $5 \%$ skimmed milk in PBST buffer) for 2 hours at room temperature and then washed 3 times with PBST. The membrane was incubated with the prepared anti-RABV-P ascites (1:1000), overnight at $4^{\circ} \mathrm{C}$. Rabbit anti-GAPDH polyclonal antibody (Goodhere Biotechnology, China) (1:1000) was used as an internal control. PageRuler ${ }^{\mathrm{TM}}$ Prestained Protein Ladder Plus (Thermo Fisher, USA) was used for controlling the electrophoretic separation rate, the efficiency of protein transfer, and the size of target protein. After 3 washes with PBST, the membrane was incubated with HRP conjugated secondary antibodies at a dilution of $1: 5000$ at $37^{\circ} \mathrm{C}$ for 1 hour. The membrane was then washed 3 times with PBST. EasySee Western Blot Kit (TransGen Biotech, China) was used to detect the immune response.

\subsubsection{Indirect Immunofluorescence Assay}

Immunofluorescence assay was performed as previously described (21). The N2a cells were infected with the HEP-Flury strain and further cultured for 36 hours. The cells were washed once with PBS, and fixed with cold acetone-methanol (1/1) for 20 minutes at $-20^{\circ} \mathrm{C}$. Next, the samples were air dried at room temperature and blocked by $5 \%$ skimmed milk. The anti-RABV-P monoclonal antibody was diluted in 1:1000 with 5\% skimmed milk as a primary antibody. Fluorescein isothiocyanate (FITC)conjugated goat anti-mouse IgG H\&L antibody (Abcam, China) was used as a secondary antibody, followed by five washes with PBS. The cells were then viewed under a fluorescence microscope.

\section{Results}

\subsection{Plasmid Construction}

A 894-bp gene fragment was amplified by RT-PCR from rabies virus infected cells. The RABV-P gene was successfully inserted to expression vector PET-32a (+) (Figure 1). Sequence analysis of the inserted phosphoprotein gene (894 bp) displayed $100 \%$ identity with the sequence published in NCBI (GenBank: AF369264.1) (data not shown); no mutation was found in the nucleotide sequence of the inserted fragment.

\subsection{Expression and Purification of the Recombinant Protein}

The confirmed pET-32a (+)-RABV-P plasmid was used to express the fusion protein in the expression host $E$. coli Rosetta (DE3). A band of approximately $50 \mathrm{kDa}$, the target protein size of the pET-32a (+)-RABV-P fusion protein, was
Figure 1. Amplification of Rabies Virus Phosphoprotein Gene

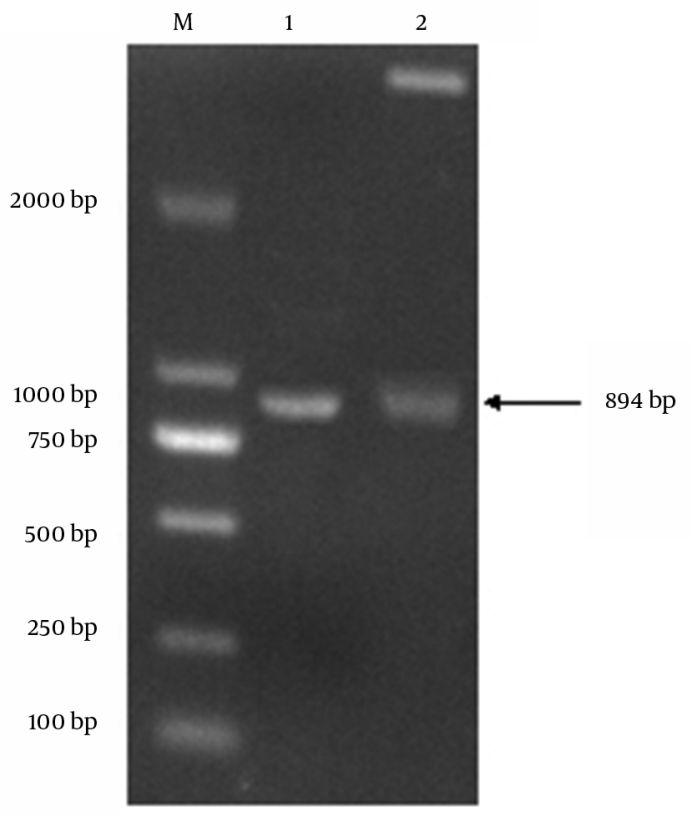

M: DL2000 DNA marker; 1: phosphoprotein gene fragment; 2: digestion production of pET-32a-P by EcoR I and Sal I Enzymes.

observed. Thus, the recombinant RABV-P was successfully expressed in the E. coli. As the recombinant protein was expressed mainly in inclusion bodies, $8 \mathrm{M}$ urea as a strong denaturant and Ni2+-affinity chromatography for purification of the recombinant protein were together added to the buffer. After binding to the resin, the target protein was successfully eluted with $250 \mathrm{mM}$ imidazole elution buffer. The collected sample was analyzed by SDS-PAGE, and a single homogeneous band of about $50 \mathrm{kDa}$ was observed (Figure 2). The purity of fusion protein was more than $90 \%$ and approximately $0.5 \mathrm{mg} / \mathrm{mL}$ of recombinant RABV-P was obtained.

\subsection{Production and Characterization of Monoclonal Antibodies} 4.3.1. Anti-RABV-P Ascites titer and Specificity Analysis by iELISA

Through cell fusion and three sub-cloning steps, one hybridoma cell line with stable secretion of specific monoclonal antibody against RABV-P, named 1A4, was obtained. After the injection of Balb/c with 1A4, according to standard protocols, ascites were collected and centrifuged at 10,000 $\times \mathrm{g}$ for 20 minutes at $4^{\circ} \mathrm{C}$, and purification of ascites by ammonium sulfate method was performed. The purification results were verified by SDS-PAGE (Figure 3). The ascites antibody titer was examined by ELISA with different consecutive dilutions, 1:2000; 1:4000; 1:8000; 1:16,000; 1:32,000; 
Figure 2. SDS-PAGE Analysis of Expressed and Purified of Recombinant RABV Phosphoprotein in E. coli

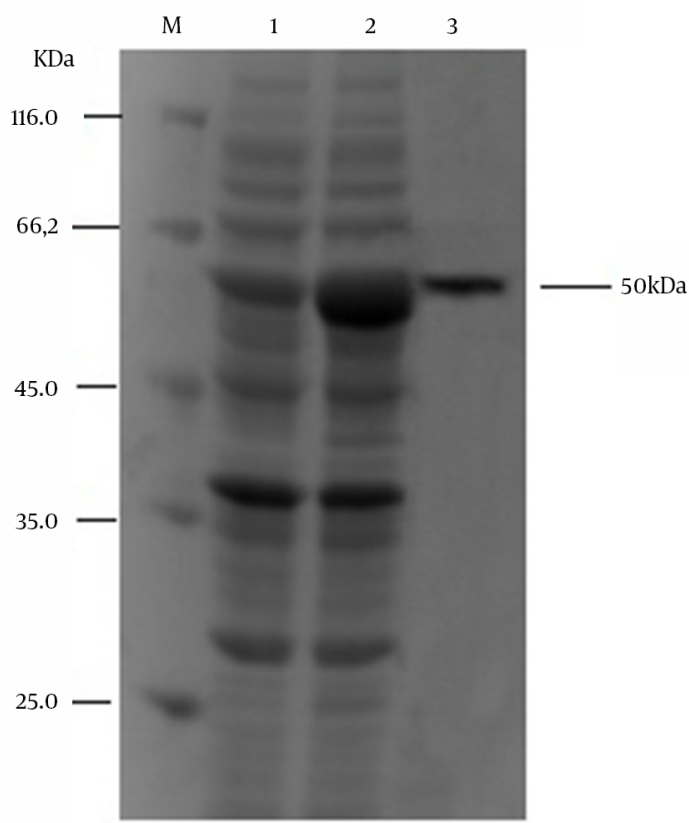

The input of sample are $10 \mu \mathrm{L}$. The lysates of E. coli before induced, after induced and purified recombinant RABV phosphoprotein were separated using 12\% SDS-PAGE gels and then stained with Coomassie brilliant blue. M: Protein Marker; 1: E. coli Rosetta (DE3) containing pET-32a-RABV-P before induced by IPTG; 2: E. coli Rosetta (DE3) containing pET-32a- RABV-P was induced with IPTG; 3: Purified recombinant RABV-P protein

1:64,000; $1: 128,000 ;$ and 1:256,000. The antibody titer was defined as the highest dilution of serum at which the A450 of ascites/A450 of negative serum was greater than 2.1. The antibody titer was approximately 1:256 000 (Table 1 ).

\subsubsection{Western Blot and Indirect Immunofluorescence Assay}

The activity and specificity of the obtained monoclonal antibody was determined with western blot and indirect immunofluorescence assay. The result of western blot showed a single band in the expected position, indicating that viral protein could be recognized by the $1 \mathrm{~A} 4$ monoclonal antibody. The lysates of mock-infected N2a cells was also incubated with the same ascites monoclonal antibody and no band was observed (Figure 4). Furthermore, immunofluorescence assay showed that RABV-infected N2a cell could be notably recognized by the $1 \mathrm{~A} 4$ monoclonal antibody and positive serum sample, compared to that in mock-infected N2a cells (Figure 5).

\subsubsection{Subtype Characterization of $m A b 1 A 4$}

The monoclonal antibody subtype of 1A4 was identified according to the instructions of the monoclonal an-
Figure 3. SDS-PAGE Analysis of the Primary Purified 1A4 Monoclonal Antibody from Ascites

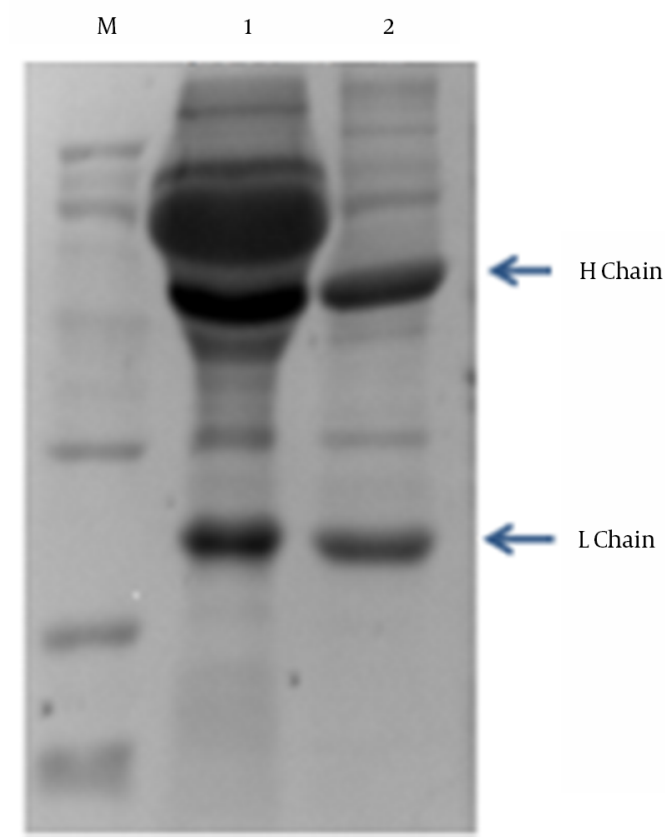

M: Protein Marker; 1: Unpurified ascites; 2: Purified ascites of mAb 1A4.

Figure 4. Reactivity of Monoclonal Antibody 1A4 with Phosphoprotein of Rabie Virus Infected Cells in Western Blot Assay

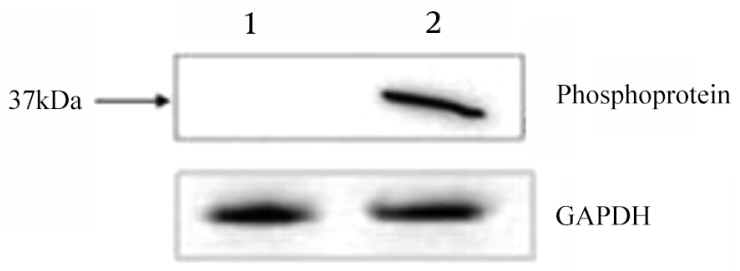

1: lysates of the N2a cells uninfected with rabies virus; 2: lysates of the N2a cells in fected with rabies virus.

tibody subtype identification kit. The result showed that 1A4 belongs to IgG1 type, and the light chain belongs to the Kappa type.

\section{Discussion}

Rabies is one of the oldest infectious diseases and is still a serious threat to public health around the world (22). Nowadays, rabies detection methods are mainly based on nucleoprotein and glycoprotein detection (23-27), and 
Table 1. Determination of Ascites Titer

\begin{tabular}{|c|c|c|c|c|c|c|c|c|c|}
\hline & 1:2000 & $1: 4000$ & $1: 8000$ & $\begin{array}{l}\text { Ascites } \\
1: 16000\end{array}$ & $\begin{array}{l}\text { Dilution } \\
\text { 1:32000 }\end{array}$ & $1: 64000$ & $1: 128000$ & 1:256000 & negative \\
\hline OD450 & 1.607 & 1.431 & 1.023 & 0.674 & 0.389 & 0.259 & 0.163 & 0.107 & 0.056 \\
\hline
\end{tabular}

Figure 5. Reactivity of Monoclonal Antibody 1A4 with Rabies Virus Infected Cells in Immunofluorescence Analysis (IFA)

N2a
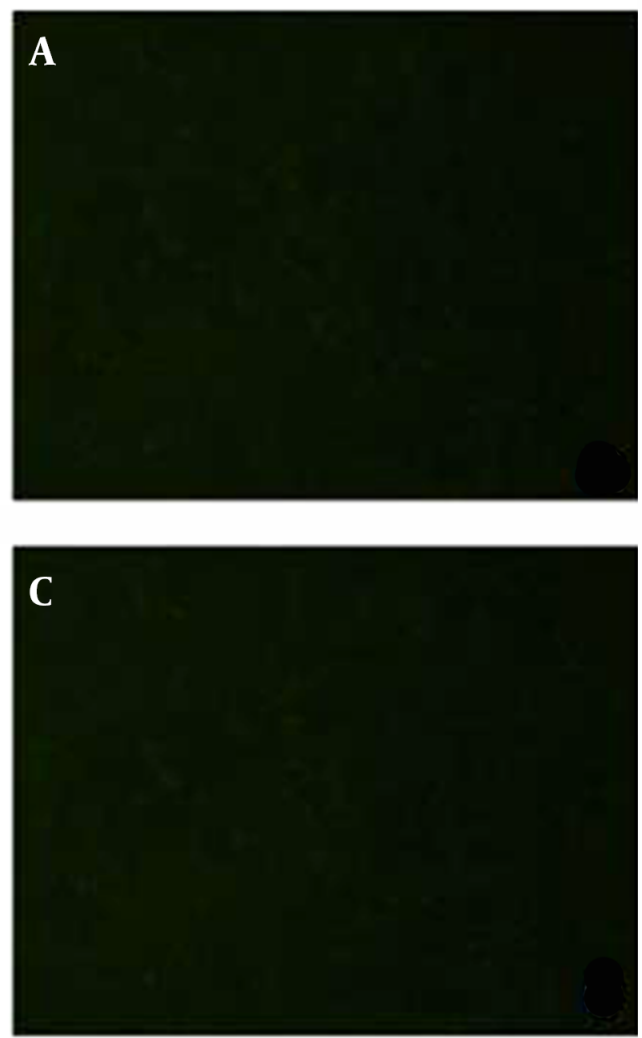

Flury-N2a

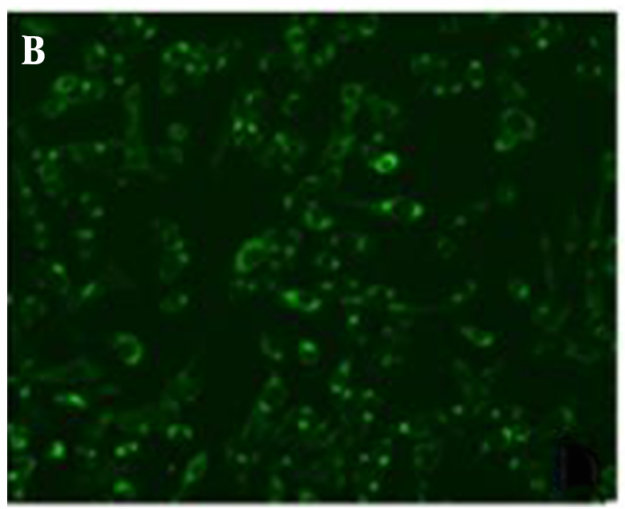

1A4

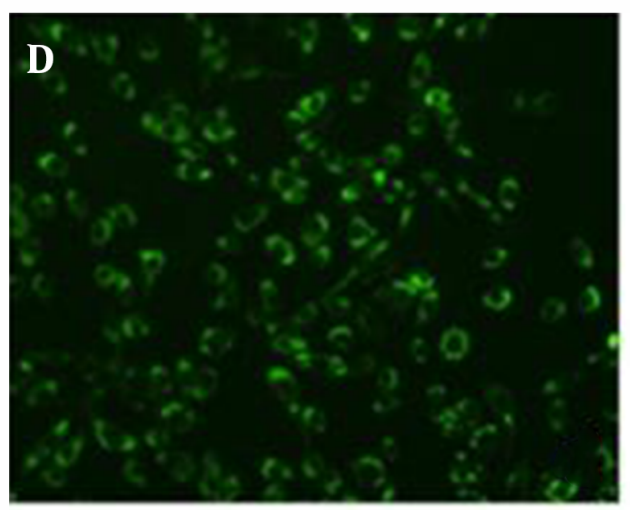

Positive

A, C are mock-infected N2a cells; B, D are the rabies virus infected N 2a cells. Anti-rabies virus serum was used as positive control.

post-exposure prophylaxis is only against G protein neutralizing antibodies. Whether P protein could be used for rabies detection is not fully known. In a previous experiment, the authors were surprised to find that a large number of anti-P protein antibodies were produced in the rabies virus HEP-Flury strain immunized mice, which greatly encouraged further investigation. Anti-P protein antibodies could provide a powerful tool for establishing the detection method of rabies virus.

The splenocytes from the immunized mice were fused with SP2/0 myeloma cells. After 3 cycles of subcloning, one anti-RABV-P mAbs hybridoma cell line $1 \mathrm{~A} 4$ was obtained.
After several repeated freezing and thawing tests, the researchers determined that the mAbs stably secreted specific antibody. Further studies will continue to track its stability. The SDS-PAGE analysis showed that the strain of $\mathrm{mAb}$ could have two distinct bands after purification (Figure 3). The current research prepares abundant recombinant $P$ protein antigen and its mAbs, and this has significant reference on the research of RABV detection kit. The prepared mAbs could provide a basis and a powerful tool for further research of the characteristics and function of P protein.

Similar works were reported previously. Raux et al. 
(28) developed 36 mAbs specific for the rabies virus recombinant P (PV strain), and the antigenic epitopes were identified, yet the immunofluorescence reactions were not shown. Zhao et al. (29) expressed the recombinant P in E. coli with pET32a expression vector, and the gene was of Hep-Flury strain, which was very similar with the materials used in this study. However, the mAb 4B5 produced by Zhao et al. (29) recognized P distributed both in the cytoplasm and nucleus, and the mAb $1 \mathrm{~A} 4$ recognized $\mathrm{P}$ mainly distributed in the cytoplasm. Full length of P of RABV, and 4 other amino-terminally truncated products (P2, P3, P4 and P5) translated from P mRNA have been found in infected cells, in the purified virus, and in cells transfected with a plasmid encoding the full length P protein gene (2). P and $\mathrm{P} 2$ are located in the cytoplasm, and P3, P4 and P5 are found mostly in the nucleus (2).

\subsection{Conclusion}

The epitopes recognized by $4 \mathrm{~B} 5$ and $1 \mathrm{~A} 4$ might be different. The mAb 1A4 was prepared from the recombinant $P$ of Hep-Flury strain of RABV, which could recognize the CVS strain (data not shown). This suggested that the recombinant phosphoprotein of the current study had conserved epitopes, which are common to both Flury strain and CVS strain. Rabies virus structural protein phosphoprotein has a high genetic stability, and also a high antigenic epitope homology with different strains; different rabies virus strains' amino acid have a 92\% to 98\% homology $(30,31)$. Therefore, monoclonal antibodies to phosphoprotein as a tool for detection of antibodies, has a good specificity.

\section{Acknowledgments}

The authors are grateful to Dr. Mi Zhang for critically reading this manuscript.

\section{Footnotes}

Authors' Contribution: Juan $\mathrm{Hu}$ carried out most of the experiments, and wrote the manuscript. Xueshan Xia and Jinyang Zhang developed the original idea and critically revised the manuscript. Ming Yang, Yuzhu Song, Qinqin Han, Qiang Chen, and Jie Zan helped in experiments and material preparation. All authors approved the final manuscript.

Financial Disclosure: The authors declare that there were no competing financial interests.

Funding/Support: This work was supported by the scientific research fund of Yunnan Provincial education department (2015Y062) and Yunnan province science and technology program (2015FB121).

\section{References}

1. Lechenne $\mathrm{M}$, Naissengar K, Lepelletier A, Alfaroukh IO, Bourhy $\mathrm{H}$, Zinsstag J, et al. Validation of a Rapid Rabies Diagnostic Tool for Field Surveillance in Developing Countries. PLoS Negl Trop Dis. 2016;10(10):e0005010. doi: 10.1371/journal.pntd.0005010. [PubMed: 27706156].

2. Chenik M, Chebli K, Blondel D. Translation initiation at alternate in-frame AUG codons in the rabies virus phosphoprotein mRNA is mediated by a ribosomal leaky scanning mechanism. J Virol 1995;69(2):707-12. [PubMed: 7815533].

3. Zhang J, Wu X, Zan J, Wu Y, Ye C, Ruan X, et al. Cellular chaperonin CCTgamma contributes to rabies virus replication during infection. J Virol. 2013;87(13):7608-21. doi: 10.1128/JVI.03186-12. [PubMed: 23637400].

4. Jackson AC. Current and future approaches to the therapy of human rabies. Antiviral Res. 2013;99(1):61-7. doi: 10.1016/j.antiviral.2013.01.003. [PubMed: 23369672].

5. Fooks AR, Banyard AC, Horton DL, Johnson N, McElhinney LM, Jackson AC. Current status of rabies and prospects for elimination. Lancet 2014;384(9951):1389-99. doi: 10.1016/S0140-6736(13)62707-5. [PubMed: 24828901]

6. Du Toit A. Viral infection: Rabies virus causes stress. Nat Rev Microbiol 2016;14(12):727. doi: 10.1038/nrmicro.2016.167. [PubMed: 27818500].

7. Knobel DL, Cleaveland S, Coleman PG, Fevre EM, Meltzer MI, Miranda ME, et al. Re-evaluating the burden of rabies in Africa and Asia. Bull World Health Organ. 2005;83(5):360-8. [PubMed: 15976877].

8. Paunescu-Podeanu A, Dinu I, Moise O. [Incidence of infectious allergic asthma].Allerg Asthma (Leipz). 1970;16(6):228-31. [PubMed: 4400070].

9. Okada K, Ito N, Yamaoka S, Masatani T, Ebihara H, Goto H, et al. Roles of the Rabies Virus Phosphoprotein Isoforms in Pathogenesis. J Virol. 2016;90(18):8226-37. doi: 10.1128/JVI.00809-16. [PubMed: 27384657].

10. Xu Y, Liu F, Liu J, Wang D, Yan Y, Ji S, et al. The co-chaperone Cdc37 regulates the rabies virus phosphoprotein stability by targeting to Hsp90AA1 machinery. Sci Rep. 2016;6:27123. doi: 10.1038/srep27123. [PubMed: 27251758].

11. Li Y, Dong W, Shi Y, Deng F, Chen X, Wan C, et al. Rabies virus phosphoprotein interacts with ribosomal protein $\mathrm{L} 9$ and affects rabies virus replication. Virology. 2016;488:216-24. doi: 10.1016/j.virol.2015.11.018. [PubMed: 26655239].

12. Liu Y, Sun L, Yu P, Li A, Li C, Tang Q, et al. Viral suppression function of intracellular antibody against C-terminal domain of rabies virus phosphoprotein. Acta Biochim Biophys Sin (Shanghai). 2015;47(10):81523. doi: 10.1093/abbs/gmv060. [PubMed: 26188200].

13. Tang HB, Lu ZL, Wei XK, Zhong YZ, Zhong TZ, Pan Y, et al. A recombinant rabies virus expressing a phosphoprotein-eGFP fusion is rescued and applied to the rapid virus neutralization antibody assay. J Virol Methods. 2015;219:75-83. doi:10.1016/j.jviromet.2015.03.022. [PubMed: 25845623].

14. Kammouni W, Wood H, Saleh A, Appolinario CM, Fernyhough P, Jackson AC. Rabies virus phosphoprotein interacts with mitochondrial Complex I and induces mitochondrial dysfunction and oxidative stress. J Neurovirol. 2015;21(4):370-82. doi: 10.1007/s13365-015-0320-8. [PubMed: 25698500].

15. Yamaoka S, Ito N, Ohka S, Kaneda S, Nakamura H, Agari T, et al. Involvement of the rabies virus phosphoprotein gene in neuroinvasiveness. J Virol. 2013;87(22):12327-38. doi: 10.1128/JVI.02132-13. [PubMed: 24027304].

16. Shimizu K, Ito N, Sugiyama M, Minamoto N. Sensitivity of rabies virus to type I interferon is determined by the phosphoprotein gene. Microbiol Immunol. 2006;50(12):975-8. [PubMed: 17179666]. 
17. Morimoto K, Shoji Y, Inoue S. Characterization of P gene-deficient rabies virus: propagation, pathogenicity and antigenicity. Virus Res. 2005;111(1):61-7. doi: 10.1016/j.virusres.2005.03.011. [PubMed: 15896403].

18. Wiltzer L, Okada K, Yamaoka S, Larrous F, Kuusisto HV, Sugiyama M, et al. Interaction of rabies virus P-protein with STAT proteins is critical to lethal rabies disease. J Infect Dis. 2014;209(11):1744-53. doi: 10.1093/infdis/jit829. [PubMed: 24367042].

19. Zhang J, Ye C, Ruan X, Zan J, Xu Y, Liao M, et al. The chaperonin CCTalpha is required for efficient transcription and replication of rabies virus. Microbiol Immunol. 2014;58(10):590-9. doi: 10.1111/13480421.12186. [PubMed: 25082455].

20. Berry JD, Jones S, Drebot MA, Andonov A, Sabara M, Yuan XY, et al. Development and characterisation of neutralising monoclonal antibody to the SARS-coronavirus. J Virol Methods. 2004;120(1):87-96. doi: 10.1016/j.jviromet.2004.04.009. [PubMed:15234813].

21. Luo J, Shi H, Tan Y, Niu X, Long T, Zhao J, et al. Two potential recombinant rabies vaccines expressing canine parvovirus virion protein 2 induce immunogenicity to canine parvovirus and rabies virus. Vaccine. 2016;34(37):4392-8. doi: 10.1016/j.vaccine.2016.07.020. [PubMed: 27449079].

22. Pan W, Ren X, Guo H, Ding Q, Zheng AC. Expression, purification of herpes simplex virus type 1 UL4 protein, and production and characterization of UL4 polyclonal antibody. J Virol Methods. 2010;163(2):465-9. doi: 10.1016/j.jviromet.2009.11.015. [PubMed: 19917314].

23. Smith TG, Ellison JA, Ma X, Kuzmina N, Carson WC, Rupprecht CE. An electrochemiluminescence assay for analysis of rabies virus glycoprotein content in rabies vaccines. Vaccine. 2013;31(33):3333-8. doi: 10.1016/j.vaccine.2013.05.081. [PubMed: 23742991].
24. Nimmagadda SV, Aavula SM, Biradhar N, Rao VS, Shanmugham $\mathrm{R}$, Chandran D, et al. Recombinant diabody-based immunocapture enzyme-linked immunosorbent assay for quantification of rabies virus glycoprotein. Clin Vaccine Immunol. 2010;17(8):1261-8. doi: 10.1128/CVI.00204-10. [PubMed: 20573881]

25. Lv XJ, Shen XX, Yu PC, Li H, Wang LH, Tang Q, et al. [Study on the B cell linear epitopes of rabies virus CVS-11 nucleoprotein]. Bing Du Xue Bao. 2014;30(3):253-6. [PubMed: 25118379].

26. Luo TR, Minamoto N, Ito H, Goto H, Hiraga S, Ito N, et al. A virusneutralizing epitope on the glycoprotein of rabies virus that contains Trp251 is a linear epitope. Virus Res. 1997;51(1):35-41. [PubMed: 9381793].

27. Luo TR, Minamoto N, Hishida M, Yamamoto K, Fujise T, Hiraga S, et al. Antigenic and functional analyses of glycoprotein of rabies virus using monoclonal antibodies. Microbiol Immunol. 1998;42(3):187-93. [PubMed: 9570284].

28. Raux H, Iseni F, Lafay F, Blondel D. Mapping of monoclonal antibody epitopes of the rabies virus P protein. J Gen Virol. 1997;78 ( Pt 1):119-24. doi: 10.1099/0022-1317-78-1-119. [PubMed: 9010294].

29. Zhao B, Huang H, Zhu S, Zhao SQ, Mao SY, Guo XF, et al, editors. Development of a monoclonal antibody that is specific for the Rabies virus phosphoprotein. IT in Medicine and Education (ITME), 2011 International Symposium on. 2011; IEEE; pp. 48-52.

30. Shoji Y, Inoue S, Nakamichi K, Kurane I, Sakai T, Morimoto K. Generation and characterization of $\mathrm{P}$ gene-deficient rabies virus. Virology. 2004;318(1):295-305. doi: 10.1016/j.virol.2003.10.001. [PubMed: 14972555].

31. Finke S, Conzelmann KK. Replication strategies of rabies virus. Virus Res. 2005;111(2):120-31. doi: 10.1016/j.virusres.2005.04.004. [PubMed: 15885837]. 